\title{
Patients' Characteristics and their Perception of Nursing Care at Rivers State University Teaching Hospital, Port Harcourt
}

\author{
Okankwu, Elizabeth Amini ${ }^{1}$, Emordi, Nnenna Ali ${ }^{2}$, Ezekiel,Rosemary ${ }^{3}$ \\ ${ }^{I}$ Department Of Nursing Sciences, Facultyof Basic Clinical Sciences, College of Medical Sciences, Rivers State \\ University Port Harcourt, Nigeria \\ ${ }^{2}$ Department Of Nursing Sciences, Faculty of Basic Clinical Sciences, College of Medical Sciences, Rivers State \\ University Port Harcourt, Nigeria \\ ${ }^{3,4}$ Rivers State Hospitals Management Board, Port Harcourt, Nigeria
}

\begin{abstract}
*Corresponding Author:Okankwu, Elizabeth Amini, Department of Nursing Sciences, Faculty of Basic Clinical Sciences, College of Medical Sciences, Rivers State University Port Harcourt, Nigeria. Email: lizzyokankwu@yahoo.com
\end{abstract}

\begin{abstract}
The study was carried out to determine patients' perception of nursing care rendered at the Rivers State UniversityTeaching Hospital Port Harcourt. The study adopted the purposive sampling technique to sample 130 patients out of a population of One thousand two hundred and eighty-six $(1,286)$ patients on admission throughout July 2019. Four research questions guided the study. The Researchers made questionnaire titled Patient Perception of Nursing Care Scale (PPNCS), which is a 4-point Likert scale ( $1=$ strongly disagree, $2=$ disagree, $3=$ agree, $4=$ strongly agree) was used to collect data for the study. Data generated was analyzed using frequency count and simple regression. Findings showed that the patients had a positive perception of the nursing care rendered at the Rivers State University Teaching Hospital Port Harcourt as reflected in their mean rating of $2.56, S D=0.29$. that age $(F=1.454,>.05)$ and educational status $(F=1.308, p>.05)$ respectively had no significant influence on patients' perception of nursing care rendered at the Rivers State University Teaching Hospital, Port Harcourt, while sex $(F=6.61, p<.05)$ had a significant influence on the patients' perception of nursing care rendered at the Rivers State University Teaching Hospital, Port Harcourt. Based on the findings, it is recommended that the nursing services department of the hospital should consolidate on their achievement by ensuring that all patients are duly cared for and that the care rendered meet and surpassed expectations. That the care rendered should be holistic and patient-centred. That supportive supervision should be carried out from time to time by the nursing services department to ensure the maintenance of the standard.
\end{abstract}

\section{INTRODUCTION}

Nurses' are key players in administering care and exhibition of clinical skills because they interact more with the patients than any other health personnel. Their services range from receiving patients to teaching and advocacy. Consequently, patients and the society at large rate the performance of any care centre based on the degree of expertise exhibited by the nurses rendering their services. Nursing care is an essential aspect of health care rendered to clients in health facilities. It is an integral part of health care management and fundamental in the overall health outcome and well-being of hospitalized patients. Based on the importance of nursing care to patient's recovery, the patients themselves have gone further to demand a moreefficient and standard care based on their knowledge of what constitutes quality care, such as timely response to their needs, right diagnosis and treatment, correct information about their health condition and appropriate education on self-care management, in other to recover quickly from their ailments, have a timely discharge from the hospital, which in other words constitute succour to their pocket.

Since patients consider the listed features as essential ingredients of what constitutes effective or ineffective nursing care, this study wishes to adopt them in determining how patients rate the performance of care the nurses at Rivers State University Teaching Hospital Port Harcourt render to them. In doing this, therefore, the term patients in this study shall 
beused to refer to those that are admitted in the centre otherwise known as inpatients. The study shall also determine if the perception of patients towards the care nurses render differ among patients on grounds of gender, age or educational qualification.

\subsection{Statement of Problem}

There is a growing complaint in recent times about nurses not being sympathetic with the patients in their care. This could be as a result of a shortage of nursing staff which has placed a lot of burden on the few working hands. More so the condition of being on admission means that patients have accepted that they cannot help themselves; and having assumed the sick role, expect to receive the best of care, attention and treatment from nurses, to put them back on their feet and make them leave the hospital as soon as possible.

Affectionate attitude towards the sick help put them in the right state of mind for the drugs to act, while unsympathetic, disrespectful behaviour towards patients makes them perceive nurses as unfriendly, rude and arrogant workers who do not pity ailing ones. This, in turn, has caused a lot of patients to express dissatisfaction with hospital care and may not want to return to such a place for treatment or even refer another, leading to poor turn-over in such hospitals. This study attempts to assess patients' perception with the care rendered at the Rivers State University Teaching Hospital in the State.

\subsection{Purpose of the study}

The purpose of the study was to determine patients' perception of the nursing care rendered at the Rivers State University Teaching Hospital. Specifically, the study tried to;

- Determine patient's perception of care rendered at Rivers State University Teaching Hospital, Port Harcourt

- Determine the influence of age on patients' perception of nursing care.

- Determine patients' perception of care received at the Rivers State University Teaching Hospital, Port Harcourt based on gender.

- Ascertain patients' perception of nursing care received at the Rivers State University Teaching Hospital, Port Harcourt based on their educational background.

\subsection{Research Questions}

The following research questions are posed to guide the study.

- How do patients perceive nursing care rendered at the teaching hospital?

- What is the influence of patients' age on their perception of nursing care?

- What are the patients' perceptions of care based on their gender?

- What is the influence of patients'educational qualification on their perceptions of nursing care rendered at the teaching hospital?

\subsection{Hypothesis}

- There is no significant relationship between patients' demographics and their perception of nursing care rendered at the Rivers State University Teaching Hospital, Port Harcourt.

\section{LITERATURE REVIEW}

Nursing care has been defined as the provision of services necessary for the promotion and maintenance or restoration of health or wellbeing of an individual or family. Quality nursing care on the other hand borders on the extent to which the care and services provided to individuals and patient populations improve desired health outcomes, it also sought to attain the highest degree of excellence in care delivery to patients. It is characterized by competence and personal caring, supported by the professionalism and delivered by an appropriate standard necessary for patients' recovery (Negussie 2018, Izumi, Bags \& Knafi 2010, and Weller 2009).

Quality nursing care means the provision of care based on set standards and represents the single most efficient and effective evaluation of health system performance. Its importance is not only to the consumer but the organization and to nursing as a profession. This is because it accounts for a short hospital stay, quick patient recovery and health promotion as well as positive evaluation that make for retention and referrals. Quality care has been described differently by nurses and patients based on their experiences. While care providers view quality care in terms of competency and practising based on set standards, consumers describe it in terms of interpersonal relationship, efficiency, competency, comfort, personalized care, physical environment, and general instructions provided on the bases of care as patients want to 
be part of their care. They expressed feelings of satisfaction when they are involved in making decisions on their care; receive useful information on when they are likely to be discharged home, explanation of activities involved in their care, teaching and useful information on the health condition that brought them to the hospital.

According to Ayyub, Kanji, Dias and Roshan (2015) patients' perceived nursing care as being qualitative when nurses respond promptly to their needs, provide care based on their expectations and concerning their human person. Patients are delighted when they have information on self-care and knowledge of how they can manage their conditions at home, as most of them dread hospital for reasons other than economics. Their expectation of nursing care does not lie only in physical components of care, but the inclusion of affective component which provides a sense of comfort and dignity for the patient and influences their perception of hospital care. Also, patients' demographics such as gender, age and educational status may have their toll on the way they perceive and feel satisfied with the nursing care they receive; which most of the previous studies have failed to examine.

Nurses are the first point of contact in many hospitals and remain the only point of contact for some patients in most hard-to-reach areas; therefore, they have the duty of providing care that meets their clients' expectation. With their unique function being to assist both sick and well in the performance of those activities that contribute to health or its recovery (or to peaceful death) which the person would have performed unaided if he had the necessary strength, will or knowledge (Henderson in Ahtisham \& Jacoline 2015), their care is highly relevant and important in hospitalized patients' outcome.

Zhao and Akkadechanunt (2011) stated that quality nursing care is the degree of excellence observed in the delivery of care to patients, and borders on both personnel and environmental characteristics exhibited and observed while providing care. These are friendly disposition, appropriate care activities, care environment that is supportive and stimulating enough to enhance recovery, well-being and progress of the whole nursing process as perceived by patients. Nurses' performance in these areas is important as they form the core of patients' judgment of care quality and which influences their perception of the care they receive. Patients' perception of the care process provides an idea about the care quality, feedback on how to determine the quality and actual evaluation of nursing care. This is important because nursing care is a core quality indicator for any health services organization; and helps in specific areas such as patients' expression of loyalty, the attraction of new patients, improvement in patients' outcomes and reduction in litigation risk (Edgar 2017). With the current competitive healthcare environment, qualitative nursing is part of hospitals strategy to retain clients. In essence, the patients continue to choose these health care facilities as their medical treatment providers and also tell others about their satisfactory experiences with them, which helps to bring in new patients.

Bhanu, (2010) opined that patients' perception of nursing care is what matters ineffective treatment outcome as it helps to build trust and increase the likelihood of the patients adhering to the treatment regimen. This, in turn, builds the level of loyalty that makes patients keep the same hospital instead of searching for another and reduce the risk litigation (Bhanu 2010). Again,meeting patients' health care need based on the standard of practice in a positive environment has been reflected in most policy statements for health professionals and nurses. For instance, the International Code of Ethics for Nurses which guides the practise of nursing globally has it that nursing care must be based on respect for human rights, including cultural rights and the right to life and choice (ICN, 2012). Inherent in this ethical code is that nursing care is unrestricted irrespective of age, colour, creed, culture, disability or illness, gender, nationality, politics, race and social status (Ella, Samson-Akpan, Mgbekem \& Edet 2016). Based on the foregoing, patients' characteristics have influenced care and the way patients perceived the care they received.

Kewi, Tesema and Negussie (2018) in their study reported positive patient perception of nursing care as most of them confessed strong interpersonal relationship with the nurses, as shown in friendly communication, respect and willingness on the part of the nurses to help a patient. Also, the involvement of patients in decisions concerning their care and nurses' response to their care in good time without any 
delay connotes quality. However, they did not find any association between patients' demographic variables such as gender, age, and their perception of nursing care, but that patients educational level influences the way they perceived nursing care as those with higher education are said to expect more from the nurses than those with lower educational level.

Similarly (Suhonen and colleagues 2012, Koberich, Feuchtinger and Farin 2016) also reported that patients' educational level has been confirmed a factor in the way they perceived nursing care when it was observed that the higher the educational level of orthopaedic and trauma patients and oncology patients, the higher their expectation and when it could not be met, it influenced their perception negatively. In the same vein (Wan, Hu, Thobaben, Hou and Yin 2011) noted thatolder patients are more tolerant, and having perceived professionals as people who are knowledgeable in their chosen profession, they show their careers more respect by being less demanding, with little or no complaints on how they feel about the care they receive.

The American Nurses Association on their part describeda patient perception of nursing care as the patient's opinion of care received from nurses during their hospitalization (Wai, ChiYang and Wen 2013). These include their expectation, hospital physical environment, communication and information, participation and involvement with care, interpersonal relationship, and nursing competence. These have been used as a yardstick to determine the overall patient satisfaction with hospital care since nurses spend the most time with patients and provide up to $80 \%$ of the healthcare they need; thus any dissatisfaction with the nursing care may indicate poor healthcare quality as well as decrease the achievement of standards in any health care organization Wai, Chi-Yang and Wen 2013, Nigussie, Hailegiorgis, Hilina, Tesfa 2017)

The issue of patients' perception of nursing care has drawn much attention at the public domain, and organizations that aim to affect people positively are trying to elicit important information required to ensure improvement in quality. Edgar (2017) observed that healthcare organizations have admitted that patients' contentment with care is one of their top priorities that must be achieved by all possible means. Therefore, examination of the quality of nursing care from the patients' perspective is one measure aimed at revealing the extent to which hospitalized patients' expectations of the health care system are met, determine their perception of the services as well as help to improve services rendered. This is because nursing care is not just about the physical aspect of care, which involves monitoring of vital signs, giving medications, nutritional care, rest, sleep and elimination to mention but few, but involves emotional and spiritual aspect too. Therefore it is important that nurses treat patients' physical ailments as well as meet their emotional and spiritual needs; so that when patients' in the hospital show anxiety about their conditions, procedures, surgeries, or recovery, it is the place of nurses to show empathy, work with patients to root out reasons for concern by explaining symptoms or helping to arrive at the proper diagnosis and appropriate treatments to ease patients' worries. This mutual collaboration, therapeutic communication and mutual respect between nurses and patients that result in positive patient outcomes are some of the characteristics that influence patients' perception of, nursing care and increase referrals and recommendation.

Several studies have tried to elicit patients' perspectives on the care they receive with the bid to ensure service improvement; this effort has revealed that patients placed more emphasis on the affective components of care which are more important in proving the quality of care needed, than nurses' technical skill. It has been observed that patients feel comfortable and are pleased with nursing care that recognized them as unique individuals with their need to share feelings, to be accepted as a family member and to have someone listen to them (Jijia, Su-mei \& Ziying 2015). Thus, juxtaposing patients' perception with quality nursing care is important to evaluate the quality of care provided and also determine how to meet patients' nursing care need in our hospitals.

A study carried out in New Delhi India by (Rasheed, Arya and Acharya 2012), to determine client's perception about health care quality at a primary care centre revealed that participants identified several factors that were detrimental to the effective delivery of quality health care, which included perceived poor attitude of some health workers, long waiting times and high cost of services. Other 
hindrances to quality care identified were inadequate staff, the policy of payment for health services, frequent referrals to other hospitals and lack of ambulances at facilities to transport the patients. Staffing issue has also been implicated in poor functioning of health facilities that may have an upsurge of patients since adequate staffing and retention are critical in the delivery of safe and effective patient care (Gullatte 2005).

Ella et al (2016) also carried out a study on factors influencing patients' perception of nurses' respect for their dignity in a public hospital in Nigeria and found that dignity was not completely maintained according to the standards expected by the patients. That Nurses' attitude towards patients had a great influence on patients' perception of nursing care and that quality of care is not only dependent on the care received, but also on the way care was delivered. Though it may seem that health care administrators in developing countries have not been very keen on judging care quality based on patients' perception as observed by (Li. Lowrie, Huang, Lu, Zhu, Wu 2015), quality nursing care is paramount in any health care organization and represents a measure of its performance; therefore nurses must understand consumers' definition of quality and ensure that they meet and exceed those expectations.

\section{Methodology}

One thousand two hundred and eighty-six $(1,286)$ patients on admission throughout July 2019 made up the population for this study (Rivers State University Teaching Hospital, Record Dept 2019). 130 patients, approximated as ten percent of the population, including male and female were selected using the purposive sampling method. Those included in the study were all patients that have spent at least 2days and above on the wards, able to communicate in English or Pidgin English, not critically ill, aged 18years and above and willing to give information freely.

Exclusion criteria included; very critically, mentally impaired, children and patients on Private wards. The wards used for the study were Male Surgical, Female Surgical, Male Medical, Female Medical, Gynae/Antenatal, Postnatal Ward.

The instrument for data collection was the Patient Perception of Nursing Care Scale (PPNCS), which is a 4-point Likert scale (1= strongly disagree, $2=$ disagree, $3=$ agree, $4=$ strongly agree).

The questionnaire items were subjected to validation by presenting them to nurse educators and a professor of nursing at the department of nursing, College of Basic Medical Sciences, Rivers State University, Port Harcourt and an educational test and measurement expert in Ignatius Ajuru University of Education. Based on their inputs, some corrections were made and the instrument deemed valid. The questionnaire was made up of thirty (30) items that addressed the research questions. Data generated were analyzed using frequency count and simple regression.

The questionnaire was only administered to the patients who had spent two (2) days and above on the wards using the face-to-face method. Those who can read and write filled theirs while others were read to. The researcher and three assistants obtained information from the participants in three days.

Approval to carry out the study was obtained from the ethical committee of the Rivers State Hospitals Management Board, Port Harcourt. Individual consent was obtained from the study subjects who signed the consent before answering the questionnaires. Confidentiality of the information obtained was maintained since the names of the study subjects were not required.

\section{RESULTS}

\subsection{Research Question 1}

How do patients perceive nursing care rendered at Rivers State University Teaching Hospital, Port Harcourt?

The result from Table 1 shows that respondents had a positive perception of the nursing care rendered at Rivers State University Teaching Hospital, Port Harcourt. The grand mean perception was $2.56, \mathrm{SD}=0.29$ and the $95 \%$ Confidence Interval moved from 2.51 to 2.62 . It is worthy of note that the respondents strongly indicated that Nurses do care for their patients $(\mathrm{M}=3.25, \mathrm{SD}=0.81)$, this was followed by the fact that they would recommend the hospital to others( $\mathrm{M}=3.06, \mathrm{SD}=1.02)$, they feel safe receiving treatment from nurses $(\mathrm{M}=2.97$, $\mathrm{SD}=0.69$ ), they perform their job skilfully $(\mathrm{M}=2.96, \mathrm{SD}=0.80)$, they ask for permission before performing any procedure $(\mathrm{M}=2.93,0.78)$ and they are satisfied with the way nurses check 
Patients' Characteristics and Their Perception of Nursing Care at Rivers State University Teaching Hospital, Port Harcourt

on patients on the ward( $\mathrm{M}=2.90, \mathrm{SD}=0.80)$ among others.

Table 1.Summary of mean perception of patients about nursing care rendered at Rivers State University Teaching Hospital, Port Harcourt

\begin{tabular}{|c|c|c|c|c|c|}
\hline & & & & \multicolumn{2}{|c|}{$95 \% \mathrm{CI}$} \\
\hline SN & items & Mean & SD & LB & UB \\
\hline 1 & Nurses do care for their patients & 3.25 & 0.81 & 3.09 & 3.41 \\
\hline 2 & Nurses treat patients with respect & 2.92 & 1.00 & 2.72 & 3.12 \\
\hline 3 & Nurses smile whenever they come to give patients treatment & 2.84 & 1.00 & 2.64 & 3.04 \\
\hline 4 & I feel safe receiving treatment from nurses & 2.97 & 0.69 & 2.83 & 3.11 \\
\hline 5 & Nurses answer patients' questions correctly & 2.85 & 0.77 & 2.70 & 3.00 \\
\hline 6 & They perform their job skillfully & 2.96 & 0.80 & 2.80 & 3.12 \\
\hline 7 & They ask for permission before performing any procedure & 2.93 & 0.78 & 2.77 & 3.09 \\
\hline 8 & They always explain any procedure before it is performed & 2.65 & 0.88 & 2.48 & 2.82 \\
\hline 9 & They render care without delay & 2.77 & 0.79 & 2.61 & 2.93 \\
\hline 10 & Respond to patients calls without delay & 2.51 & 0.92 & 2.33 & 2.69 \\
\hline 11 & The nurses are rude to patients & 1.98 & 1.06 & 1.77 & 2.19 \\
\hline 12 & Nurses are not skillful at their job & 1.95 & 0.89 & 1.77 & 2.13 \\
\hline 13 & They appear too busy to listen to patients & 2.27 & 0.87 & 2.10 & 2.44 \\
\hline 14 & It's hard to get nurses attention quickly & 2.25 & 0.88 & 2.08 & 2.42 \\
\hline 15 & Patients usually wait a long time for their treatment & 2.19 & 0.88 & 2.01 & 2.37 \\
\hline 16 & Nothing is done to remove patients' mind from the illness. & 2.38 & 0.84 & 2.21 & 2.55 \\
\hline 17 & Nurses do not explain procedures and treatment to patients. & 2.02 & 0.89 & 1.84 & 2.20 \\
\hline 18 & Nurses appear not to be knowledgeable about patients' illnesses. & 1.73 & 0.97 & 1.54 & 1.92 \\
\hline 19 & Nursing care does not meet your expectation. & 2.15 & 0.99 & 1.95 & 2.35 \\
\hline 20 & Patients do not feel loved and respected. & 2.11 & 1.00 & 1.91 & 2.31 \\
\hline 21 & Nurses encourage their patients all the time & 2.69 & 1.10 & 2.47 & 2.91 \\
\hline 22 & They touch their patients anytime they are carrying out nursing care & 2.72 & 1.02 & 2.52 & 2.92 \\
\hline 23 & Nurses involve patients in the plan of care & 2.38 & 0.87 & 2.21 & 2.55 \\
\hline 24 & Nurses give useful information on disease conditions & 2.63 & 0.94 & 2.44 & 2.82 \\
\hline 25 & Educate patients on the management of disease conditions & 2.63 & 0.97 & 2.44 & 2.82 \\
\hline 26 & Patients are happy with nursing care & 2.61 & 1.08 & 2.40 & 2.82 \\
\hline 27 & You are happy with the nursing care you receive & 2.83 & 0.99 & 2.63 & 3.03 \\
\hline 28 & You are satisfied with nurses' friendly disposition & 2.81 & 0.85 & 2.64 & 2.98 \\
\hline 29 & You are satisfied with the way nurses check on patients on the ward. & 2.90 & 0.80 & 2.74 & 3.06 \\
\hline 30 & You would recommend this hospital to others & 3.06 & 1.02 & 2.86 & 3.26 \\
\hline & Grand mean & 2.56 & 0.29 & 2.51 & 2.62 \\
\hline
\end{tabular}

\subsection{Research Question 2}

Whatare the patients' perceptionsof nursing care based on their ages?

Table 2. Summary of descriptive statistic on patients' perception of nursing care based on their ages

\begin{tabular}{|l|l|l|l|l|l|}
\hline $\begin{array}{c}\text { Age range } \\
\text { (years) }\end{array}$ & $\mathbf{N}$ & $\begin{array}{c}\text { Minim } \\
\text { um }\end{array}$ & $\begin{array}{c}\text { Maxi } \\
\text { mum }\end{array}$ & $\begin{array}{c}\text { Mea } \\
\text { n }\end{array}$ & SD \\
\hline $15-24$ & 8 & 2.13 & 2.60 & 2.38 & 0.15 \\
\hline $25-34$ & 26 & 1.97 & 3.10 & 2.57 & 0.33 \\
\hline $35-44$ & 25 & 1.87 & 3.07 & 2.66 & 0.26 \\
\hline $45-54$ & 20 & 2.07 & 3.00 & 2.55 & 0.24 \\
\hline $55-64$ & 9 & 1.63 & 3.20 & 2.54 & 0.43 \\
\hline $65>$ & 12 & 1.97 & 2.83 & 2.52 & 0.29 \\
\hline
\end{tabular}

The results from Table 2 and Figure 1 showed a summary of descriptive statistic on patients' perception toward nursing care based on their ages. It showed that the patients in the age bracket of 35-44 years had the best perception towards nursing care with a mean rating of 2.66 and a standard deviation of 0.26 . This was followed by those in the age bracket of 25-34 years who had a mean perception of 2.57 and a standard deviation of 0.33 . The least was the age range of 15-24 years who had a mean perception of 2.38 and a standard deviation of 0.15 .

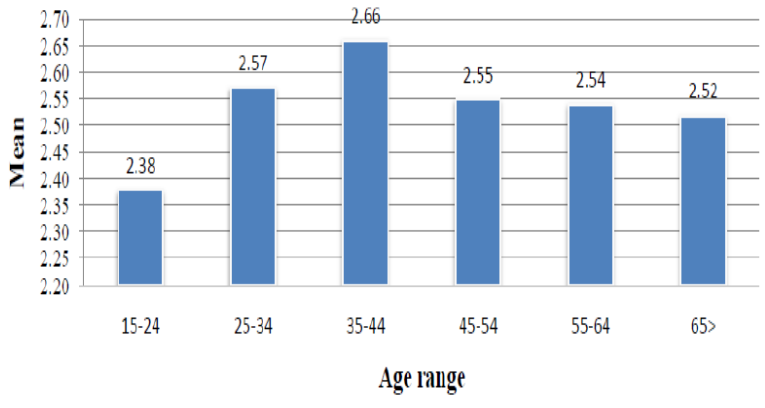

Fig. 1.Mean perception of patients about nursing care based on age 


\subsection{Research Question 3}

What is the influence of gender on patients' perception of nursing care?

Table 3. Summary of descriptive statistics on patients' perception of nursing care based on gender

\begin{tabular}{|l|c|l|l|l|l|}
\hline \multicolumn{1}{|c|}{ Sex } & $\mathbf{N}$ & \multicolumn{1}{|c|}{$\begin{array}{c}\text { Minimu } \\
\text { m }\end{array}$} & $\begin{array}{c}\text { Maxim } \\
\text { um }\end{array}$ & \multicolumn{1}{|c|}{ Mean } & SD \\
\hline Male & 40 & 1.63 & 2.97 & 2.46 & 0.30 \\
\hline $\begin{array}{l}\text { Fem } \\
\text { ale }\end{array}$ & 60 & 1.87 & 3.20 & 2.64 & 0.26 \\
\hline
\end{tabular}

The result from Table 3 and Figure 2 shows the summary of descriptive statistics on patients' perception of nursing care based on gender. It shows that the mean perception of the male patients was 2.46 with a standard deviation of 0.30 whereas the mean perception of the female patients was 2.64 with a standard deviation of 0.26 . The result showed that female patients had a better perception of nursing care based on the mean score.

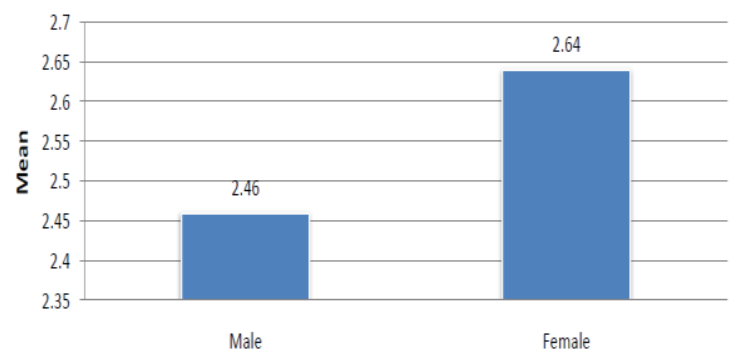

Fig 2. Mean Perception of pnts about Nursing Care based on sex

\subsection{Research Question 4}

What is the influence of educational status on patients' perception of nursing?

Table 3. Summary of descriptive statistics on patients' perception of nursing care based on educational status.

\begin{tabular}{|l|l|l|l|l|l|}
\hline $\begin{array}{l}\text { Education } \\
\text { al status }\end{array}$ & $\mathbf{N}$ & $\begin{array}{c}\text { Minim } \\
\text { um }\end{array}$ & $\begin{array}{c}\text { Maxi } \\
\text { mum }\end{array}$ & $\begin{array}{c}\text { Mea } \\
\mathbf{n}\end{array}$ & SD \\
\hline $\begin{array}{l}\text { Non } \\
\text { formal } \\
\text { Education }\end{array}$ & 3 & 2.57 & 2.77 & 2.70 & 0.12 \\
\hline $\begin{array}{l}\text { Primary } \\
\text { education }\end{array}$ & 9 & 1.97 & 2.83 & 2.51 & 0.26 \\
\hline $\begin{array}{l}\text { School } \\
\text { certificate }\end{array}$ & 28 & 2.13 & 3.10 & 2.55 & 0.25 \\
\hline Diploma & 11 & 2.07 & 3.00 & 2.63 & 0.31 \\
\hline Degree & 34 & 1.63 & 3.00 & 2.49 & 0.33 \\
\hline $\begin{array}{l}\text { Higher } \\
\text { Degree }\end{array}$ & 15 & 2.00 & 3.20 & 2.72 & 0.26 \\
\hline
\end{tabular}

The result from Table 3 shows the summary of descriptive statistics on patients' perception of nursing care based on educational status. It shows that the respondents with a higher degree had the best perception of nursing care with a mean perception of 2.72 and a standard deviation of 0.26 . This was followed by those who had non-formal education with the mean perception of 2.70 and a standard deviation of 0.12 . The least were those with a degree who had a mean perception of 2.49 and a standard deviation of 0.26 .

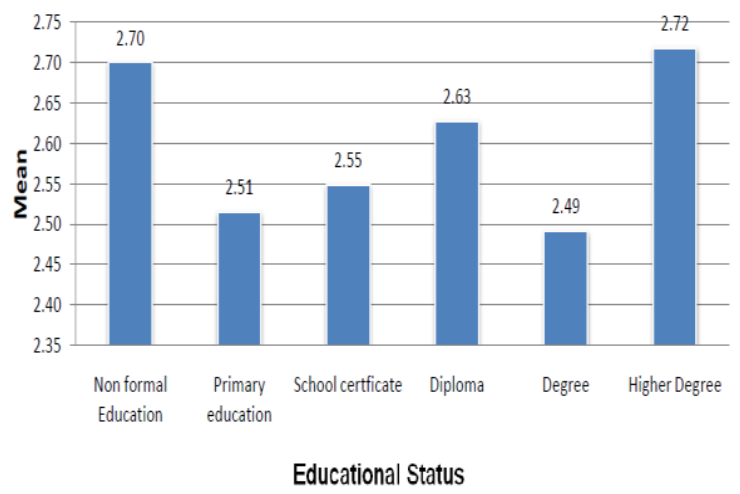

Fig 4. Mean perception of patients about nursing care based on educational status

\subsection{Hypotheses}

There is no significant relationshipbetween patients' demographics and their perception of nursing care rendered at the Rivers State University Teaching Hospital, Port Harcourt

Table 5. Summary of Factorial design Analysis of variance on the influence of patients' demographics and their perception of nursing care rendered at the Rivers State University Teaching Hospital, Port Harcourt

\begin{tabular}{|l|l|l|l|l|l|}
\hline \multicolumn{1}{|c|}{ Source } & $\begin{array}{l}\text { Type III } \\
\text { Sum of } \\
\text { Squares }\end{array}$ & df & $\begin{array}{c}\text { Mean } \\
\text { Square }\end{array}$ & F & Sig. \\
\hline $\begin{array}{l}\text { Corrected } \\
\text { Model }\end{array}$ & 1.752 & 11 & .159 & 2.083 & .030 \\
\hline Intercept & 279.852 & 1 & 279.852 & $\begin{array}{l}3660.6 \\
25\end{array}$ & .000 \\
\hline Age & .556 & 5 & .111 & 1.454 & .213 \\
\hline Sex & .506 & 1 & .506 & 6.613 & .012 \\
\hline Education & .500 & 5 & .100 & 1.308 & .268 \\
\hline Error & 6.728 & 88 & .076 & & \\
\hline Total & 666.231 & 100 & & & \\
\hline $\begin{array}{l}\text { Corrected } \\
\text { Total }\end{array}$ & 8.480 & 99 & & & \\
\hline a. R Squared = .207 (Adjusted R Squared = .107) \\
\hline
\end{tabular}

Table 5 shows the summary of Factorial design Analysis of variance on the relationship between patients' demographics and their perception of nursing care rendered at the Rivers State University Teaching Hospital, Port Harcourt. The result shows that age $(\mathrm{F}=1.454,>.05)$ and 
educational status $(\mathrm{F}=1.308, \mathrm{p}>.05)$ respectively had no significant influence on the perception of nursing care rendered at the Rivers State University Teaching Hospital, Port Harcourt. The null hypotheses were retained at .05 level of significance. However, $\operatorname{sex}(\mathrm{F}=6.61, \mathrm{p}<.05)$ had a significant influence on the perception of nursing care rendered at the Rivers State University Teaching Hospital, Port Harcourt. The null hypothesis was rejected in this case at .05 alpha levels.

\section{DISCUSSION OF FINDINGS}

\subsection{Perception of Patients about Nursing Care Rendered at Rivers State University Teaching Hospital, Port Harcourt}

The result from Table 1 showed that the patients had a positive perception of the nursing care as reflected in their mean rating of $2.56, \mathrm{SD}=0.29$ which is above the criterion mean score of 2.50 on a 4-point rating scale. when put to the statistical test, the result on Table 5 showed that age $(\mathrm{F}=1.454,>.05)$ and educational status $(\mathrm{F}=1.308, \mathrm{p}>.05)$ respectively had no significant influence on the perception of nursing care rendered at the Rivers State University Teaching Hospital, Port Harcourt, while sex $(\mathrm{F}=6.61$, $\mathrm{p}<.05)$ had a significant influence on the patients' perception of nursing care rendered at the Rivers State University Teaching Hospital, Port Harcourt. The null hypothesis was rejected in this case at .05 alpha levels. The present finding is consistent with an earlier finding of (Jijia, Su-mei \& Ziying 2015), which established that irrespective of patients status or characteristics, their concern is more on the affective components of care which allow them to share feelings, to be accepted as a family member and to have someone listen. This they said makes patients feel comfortable are pleased as they are and treated as unique individuals. Jijia et al (2015) noted that patients see this aspect of care as one that represents the desired care quality rather than the technical skill of nurses. (Kewi, Tesema and Negussie 2018) on their part reported higher expectation of care on the part of patients with higher educational level. However, they want a confirmatory study from other researchers to establish an association of negative perception nursing care with patients' educational status.

\subsection{The Patients' Perceptions of Nursing Care Based On Their Ages}

The results from Table 2 and Figure 1 showed a summary of descriptive statistic on patients' perception toward nursing care based on their ages. It showed that the patients in the age bracket of 35-44 years had the best perception towards nursing care with a mean rating of 2.66 and a standard deviation of 0.26 . This was followed by those in the age bracket of 25-34 years who had a mean perception of 2.57 and a standard deviation of 0.33 . The least was the age range of 15-24 years who had a mean perception of 2.38 and a standard deviation of 0.15 . However, when put to the statistical test the result shows that age $(\mathrm{F}=1.454,>.05)$ had no significant influence on the perception of nursing care rendered at the Rivers State University Teaching Hospital, Port Harcourt. The null hypotheses were retained at.05 level of significance. This finding agrees with the finding of (Kewi, Tesema and Negussie 2018) which established that there was no association between patients' age and their perception of nursing care.

The variations in the findings on age and patient's perception of nursing care in Table 2 can further be explained in terms of their era in life. The patients aged 15-24years are the youngest age cohort in the study and are the ones that rated nursing care poorly. This could be related to that fact that they have not hard enough experience of everything in life, and so have no standard with which to measure their experience in the hospital; compared to the adults and older patients who have heard several life experiences that formed a yardstick for their measurement. If the patients in time past have hard people treated them badly, then they will be extremely grateful to one who tended them on the sick bed and performs most of the activities of daily living which were difficult to perform as a result of illness. Again (Wan, et al 2011) also reported thatolder patients are more tolerant and that they perceived professionals as people who are knowledgeable in their chosen professions, they show their careers more respect by being less demanding, with little or no complaints on how they feel about the care they receive.

\subsection{The Influence of Gender on Patients' Perception Of Nursing Care}

The result from Table 3 and Figure 2 shows the summary of descriptive statistics on patients' perception of nursing care based on gender. It shows that the mean perception of the male patients was 2.46 with a standard deviation of 0.30 whereas the mean perception of the female 
patients was 2.64 with a standard deviation of 0.26 . The result showed that female patients had a better perception of nursing care based on the mean score. Also, the result of statistical test on Table 5 shows that $\operatorname{sex}(\mathrm{F}=6.61, \mathrm{p}<.05)$ had a significant influence on the perception of nursing care rendered at the Rivers State University Teaching Hospital, Port Harcourt, making the null hypothesis to be rejected at .05 alpha level of significance. This result agrees with the reports of ( Kewi, Tesema and Negussie 2018, Elliott, Lehrman, Beckett and Goldstein 2012, Foss 2002) which did not find any association between patients' gender and their perception of nursing care; and that female inpatients as against their male counterparts expressed less satisfaction with all aspects of nursing care. The variation in the perception of male and female patients in the nursing care rendered at the teaching hospital may not be far from the differences and variations in their personality and social behaviours as observed by (Giudice 2015). Again, it is easier for females to

\subsection{The influence of educational status on patients' perception of nursing}

The result from Table 3 shows the summary of descriptive statistics on patients' perception of nursing care based on educational status. It shows that the respondents with a higher degree had the best perception of nursing care with a mean perception of 2.72 and a standard deviation of 0.26 . This was followed by those who had non-formal education with a mean perception of 2.70 and a standard deviation of 0.12 . The least were those with a degree who had a mean perception of 2.49 and a standard deviation of 0.26 . this finding is in agreement with (Kewi, Tesema and Negussie 2018), which established that patients educational level influences the way they perceived nursing care as those with higher education are said to expect more from the nurses than those with lower educational level, but did not state that they perceived it as being adequate or not. This maybe as a result of the upsurge in internet diagnosis among the elites that make patients feel like knowing, as well as management of their health condition. It is on this knowledge they base their expectations when in-hospital care and forget that what they want from care providers may not align with the healthcare organization practice.

\section{CONCLUSION}

Patients' perception of nursing care was positive irrespective of age, gender and educational attainment. However, there is the need for the nursing services department to ensure clientcentred care in the hospital as patients' recovery from ailments does not only depend on physical care but the affective component of care. This will, in turn, improve the quality of nursing care and patient satisfaction.

\section{REFERENCES}

[1] Ahtisham, Y and Jacoline, S (2015) Integrating Nursing Theory and Process into Practice; Virginia's Henderson Need Theory. Retrieved 20/5/19 from http:// www.international journal ofcaringsciences. org/docs/23_ahtisham.pdf

[2] Ayyub R, Kanji Z, Dias J, Roshan R (2015) Perceptions of Patients Regarding Quality Nursing Care (QNC) at a Tertiary Care Hospital in Karachi, Pakistan. Ritreve 10/5/19 from https://www.longdom .org

[3] Bhanu, P (2010) Patient Satisfaction. Retrieved 21/4/19 from https://www.ncbi.nlm.nih.gov/ pmc/articles/PMC3047732/

[4] Edgar, H (2017) Patient Satisfaction - Why It Matters and How to Improve It. Retrieved on 12/4/19 from https:// www.practicebuilders. com/blog/patient-satisfaction-why-it-matters/

[5] Ella R, Samson-Akpan P. E, Mgbekem, M. A, Edet, G (2016) Factors influencing patients perception of nurses respect for their dignity in a public hospital in calabar. International Journal of Humanities Social Sciences and Education (IJHSSE) Volume 3, Issue 8

[6] Elliott M.N, Lehrman W.G, Beckett. M and Goldstein. E (2012) Gender Differences inPatients' Perceptions of Inpatient Carehttps:// www.researchgate.net

[7] Foss, I.C (2002), Gender-Related Differences in Patient Satisfaction with the Quality of Nursing Carehttps://www.researchgate.net/ profile/ Ingrid /_foss

[8] Giudice, M.D (2015) Gender Differences in Personality and Social Behavior USA. Elsevier Ltd.

[9] Gullatte, M. M (2016) Nursing Management Principles and Practice. USA. ONS Publishing Division.

[10] Gupta, B. S., S. Shrestha, and B. K. Thulung 2014. "Patient's Perception towards Quality Nursing Care. Retrieved 20/5/19 from https:// www.ncbi.nlm.nih.gov

[11] ICN (2012) international code of ethics for nurses. Retrieved 10/4/19 from https:// www.icn.chIzumi,S Bags J. G and Knafi, K. A 
(2010) quality nsg care for hospilized pts with advanced illness; concept dev. Retrieved 21/5/19 from https://www. mcbi.nlm.nih.gov

[12] Jijia KM, Su-mei H, Ziying S (2015) A study of the changing health care environment to meet patient's needs and expectations. 2: 541-544.

[13] Li M, Lowrie DB, Huang C, Lu X, Zhu Y, Wu X, et al. (2015) Use of the servqual scale. Asian Pac J Trop Biomed. Elsevier 5: 497-504.

[14] Naidu, A 2009 factors affecting patients' satisfaction and healthcare quality. Retrieved 15/ 5/19from https://www.ncbi.nlm.nih.gov.

[15] Negussie, B. B (2018) Patient's Perception towards Quality of Nursing Care in Inpatient Department at Public Hospitals of Benishangul Gumuz Regional State, North WestEthiopia. Retrieved 20/5/19 from https://www.omicson line.org

[16] Nigussie, T. S, Hailegiorgis, T.B, Hilina, K. A and Tesfa, D. H (2017) Patient satisfaction and quality of care in us hospitals. 20/5/19 https:/ /bmjopen.bmj.com/content/8/5/e021107

[17] Rasheed N, Arya S, Acharya A (2012) Client Satisfaction and Perceptions About Quality of Health Care at a Primary Health Centre of Delhi, India. Journal of Community Health. https://www.researchgate.net

[18] Wai M. T, Chi-Yang S and Wen C. L (2013) Patient Satisfaction with Nursing Care: A Descriptive Study Using Interaction Model of Client Health Behavior, International Journal of Nursing Science, Vol. 3 No. 2, pp. 51-56.

[19] Weller, B.F (2009) Bailliere's nurses dictionary for nurses and health care workers. $25^{\text {th }}$ ed.New York. Elsevier Science Ltd.

[20] Xesfingi, S and Vozikis, A (2016) patient satisfaction with the healthcare system: Assessing the impact of socio-economic and healthcare provision factors. Retrieved 12/4/19 fromhttps://www.ncbi.nlm.nih.gov/pmc/articles /PMC4793546/

Citation: Okankwu Elizabeth Amini, Emordi, Nnenna Ali, Ezekiel Rosemary. Patients' Characteristics and their Perception of Nursing Care at Rivers State University Teaching Hospital, Port Harcourt.ARC Journal of Public Health and Community Medicine. 2020; 5(2):13-22. DOI: dx.doi.org/10.20431/2456-0596.0502002.

Copyright: (C) 2020 Authors. This is an open-access article distributed under the terms of the Creative Commons Attribution License, which permits unrestricted use, distribution, and reproduction in any medium, provided the original author and source are credited. 